\title{
Model for Research into the Factors Influencing the Effective Planning and Management of Production Capacity
}

\author{
Krasimira Dimitrova ${ }^{1}$, Tanya Panayotova $^{1}$, Neli Veleva $^{2}$ \\ 1- Technical University of Varna, Department of Industrial Managment, 9010, 1 Studentska Street, Varna, Bulgaria \\ 2 -PhD student, Technical University of Varna, Department of Industrial Managment, 9010, 1 Studentska Street, Varna, Bulgaria \\ Corresponding author contact: neli_velevadtu-varna.bg
}

\begin{abstract}
In today's dynamic business environment, the success and competitiveness of any production organization is ensured by continuous improvement, sustainable development, effective planning and management. There is a growing scientific interest in the importance and relevance of production management in view of the strong need to redefine the policies and priorities within the respective strategic plan for business development - with increased focus on capacity planning in order for the industrial enterprises to adapt successfully to the dynamically changing conditions of the global environment and intense competition. Accordingly, full advantage is taken from the ample opportunities to study the impact of a number of factors on capacity planning and management. Based on an in-depth literature analysis, interviews and surveys, selected were 18 key factors that have a profound influence on the effective planning and capacity management of the production organization. Using the relationship between each of these factors and the capacity management is closely examined by applying the method of Interpretive Structural Modeling (ISM). Additionally, the interrelationships between the key factors under study are further analyzed by means of a Structural self-interaction matrix (SSIM).
\end{abstract}

Keywords: effective planning and management, production capacity, factors, self-interaction matrix, Interpretive Structural Modelling.

\section{$1 \quad$ Introduction}

Solving modern problems related to the planning and management of production capacity is vital for every industrial organization. In the context of dynamic and intensified competition, fast evolving globalization, and rapid deployment of new technologies, it is extremely important for the normal course of the production processes and enhanced economic efficiency of the industrial companies that continuous development and improvement of the production management is necessary. This raises the need to identify, analyze and evaluate those key factors that have a strong effect on the processes of planning and management of production capacity, their interconnectedness and potential consequences.

The transformation of industrial enterprises into flexible and efficient organizations, tailored and coordinated with the requirements of consumers and customers, is one of the main drivers whose positive results lead to the improvement of the organization (Krishnaswamy, 2006).

The aim of the present study is to identify and classify the key factors that are likely to make a powerful impact on the production management of a given enterprise.

The main tasks related to achieving the goal:

1. Definition and analysis of the essence of the concept of "production capacity" in the industrial enterprise;

2. Determining the main characteristics and the fundamental principles of the effective planning and management of the production capacity in the industrial enterprise;

3. Identification of key factors influencing the effective planning and management of production capacity. 
4. Study of the relationship between the identified key factors and capacity management, based on the method of Interpretive Structural Modeling (ISM) and organizational coordination model in Concurrent Engineering;

5. Analysis of the relationships between the key factors under study, using a Structural selfinteraction matrix (SSIM) and their classification into 4 main categories: independent, dependent, interdependent, driving;

6. To develop a structural model of the interaction of those key factors.

The object of the study - industrial enterprises.

The subject of the study - factors influencing the effective planning and management of the production capacity of the industrial enterprise.

\section{Production capacity - nature and characteristics}

In its essence, production capacity is a dynamic quantity, the knowledge of which allows the industrial organization to clearly define, plan and manage all its production assets and tasks to achieve sustainable development and improvement, related to both production technology and synchronization of production with market demand and the goals of the enterprise.

Dima, (2013) author of "Industrial Production Management in Flexible Manufacturing Systems" accepts ,production capacity as the maximum production that can be achieved over the time for a certain structure and quality of production, under conditions of full, intensive and extensive use of production factors, according to the most efficient mode of operation and rational organization of production and work"

The author of "Production and Operations Management" Chase (Chase, 1998) understands production capacity as the volume of output of products (or services) that an enterprise can achieve at a given point in time.

According to Sushil Gupta, Martin Starr (Gupta \& Starr, 2014), "production capacity includes the number of working days in each month, the number of shifts, the number of workers, overtime permits, the maximum number of units that can be subcontracted ( outsourcing) 'and adopt the following definition: ,production capacity is the number of units that can be produced in one shift during the regular time by a given number of workers".

According to Makedonska and Dimitrov, (1997) the essence of production capacity consists in "the volume produced at the degree of maximum". (Makedonska \& Dimitrov, 1997)

The term "production capacity" has been studied many times in the scientific and popular science literature. Based on the literature review made in the present study on clarifying the nature of the concept of "production capacity" of an industrial enterprise, the following conclusions are made:

1. In the field of production management, there is no generally accepted and clearly defined definition related to the planning and capacity management of an industrial enterprise. Some authors, such as Whybark, describe these basic management methods with the term "production capacity", others (Chase, 1998) accept the term "production capacity", and still others (Dima, 2013), (Gupta \& Starr, 2014) explore and use the name "capacity". The essence of the mentioned terminological concepts and its more detailed examination is not the subject of the present study. In the present study, it is assumed that all the above concepts are synonymous.

2. There is no precisely and clearly defined sequence of necessary actions and decisions in planning and management of the production capacity of the industrial organization.

3. In theoretical and practical aspect, the factors that play a key role in achieving effective planning, control and management of production capacity are not thoroughly considered, analyzed and classified.

4. Undiscovered opportunities to explore the impact of a number of factors on capacity planning and management have been identified. 


\section{Effective planning and management of production capacity - nature and characteristics}

The production capacity (power) of the company is the maximum possible quantity and quality of products that can be produced by a production system. The production capacity is quantified during the design of the production plant and depends on the type and number of machines, equipment and production areas and their production technical parameters. Understanding, effectively planning and managing production capacity allows each organization to evaluate its future financial results and create a reliable schedule for delivery of products to its customers. The choice of approach for improvement and development of the production capacity is of utmost importance for the efficient functioning of the entire production system of the industrial company. The study of the factors influencing the effective planning and management of the production capacity is part of a unified strategy for the development of the whole enterprise. Changes in resource flexibility and resource location must be judged against the capacity reserve arising from these changes. and a number of factors that increase or decrease the company's risks. These factors that affect production capacity are related to such a level that a change in one factor potentially affects others.

No system can operate at full capacity for a long period of time. Inefficiency and delays make it impossible to achieve the maximum theoretical level of production in the long run. Without planning the use and increasing the production capacity of the enterprise, all business achievements of the production complex will be short-term. Capacity planning requires management to identify, analyze, and monitor key factors influencing the organization's performance.

After an in-depth literature review and research in real production enterprises, within the project PD4/2020, factors influencing the processes related to the effective planning and management of production capacity have been identified. They are summarized and presented in Table 1.

Table 1. Factors playing a key role in the planning and management of production capacity.

\begin{tabular}{|c|c|l|}
\hline № & Definition & Factors playing a key role in the planning and management of production capacity \\
\hline 1 & F1 & Commitment of top management \\
\hline 2 & F2 & Corporate and production strategy \\
\hline 3 & F3 & Resource planning \\
\hline 4 & F4 & Planning and effective management of production capacity \\
\hline 5 & F5 & Level of production organization \\
\hline 6 & F6 & Mechanization and automation of production \\
\hline 7 & F7 & Degree of efficiency of use of production equipmen \\
\hline 8 & F8 & Planning and implementation of maintenance and maintenance of production equipment \\
\hline 9 & F9 & Structure and functions of the management system \\
\hline 10 & F10 & $\begin{array}{l}\text { Degree of use of information technologies and software products in the horizontal and } \\
\text { vertical communication in the organization }\end{array}$ \\
\hline 11 & F11 & Effective communication and coordination between the units in the organization \\
\hline 12 & F12 & Rational use of resources \\
\hline
\end{tabular}




\begin{tabular}{|c|l|l|}
\hline 13 & F13 & Workforce qualification management \\
\hline 14 & F14 & Employee commitment to the goals of the organization \\
\hline 15 & F15 & Organizational culture \\
\hline 16 & F16 & Analysis of the results of management decisions, risks, benefits and feedback \\
\hline 17 & F17 & Flexibility and timely response in case of a problem \\
\hline 18 & F18 & $\begin{array}{l}\text { Using management methods and techniques to deal with current problems and their } \\
\text { consequences }\end{array}$ \\
\hline
\end{tabular}

Commitment of the top management. It consists in building an active relationship between the goals and the vision of the top management for development and improvement of the industrial enterprise. The main driving forces here are the desire, motivation, abilities and principles of top managers to achieve coherence and equivalence between organizational goals and requirements of end users. (Ahire \& O'Shaughnessy, 1998), (Wasif, 2016)

Corporate and production strategy. The influence of these strategies on the effective planning and management of production capacity is expressed in ensuring coordination of the production function with the other functional units for making tactical and strategic decisions, with the help of which the industrial enterprise to provide and maintain a competitive advantage. (Swamidass, 2000), (Brönner et al., 2020)

Resource planning. This is a long and strictly specific process, including identifying the current state of the industrial enterprise, setting specific goals and objectives, developing a sequence of activities for their implementation and execution, analysis of the results and receiving feedback based on which determines follow-up actions for improvement and upgrading. (Burns et al. 1991), (Umble et al., 2003)

Enterprise Resource Planning (ERP) systems help organizations manage their business efficiently and flexibly. They cover all aspects of the business: finance, manufacturing, retail, supply chain, warehouse and inventory management. This is an important tool for combining the operations of different departments that companies need to manage. ERP systems integrate various earlier processes, solve communication problems between different departments, provide capabilities that were not available in the old systems, and also provide valuable information and provide full visibility of workflows. (Olhager, 2013). (Schmitt et al. 1984)

Level of production organization. The peculiarities of the production process in the industrial enterprise presuppose the observance of some basic principles, designed to ensure the uniform implementation of the level of the different production units (section, workshop, plant) to achieve the main goal - proper planning and management of production facilities. (DuBrin, 2008)

Mechanization and automation of production have an impact on the production plant to significantly improve the quality of products and production management. Proper application and use of mechanization and automation of production, helps to reduce production time, prevent quality errors (Sharpe, 1979), (Winroth et al., 2006) better control over all stages of the production process, etc.

The overall degree of the equipment effectiveness, the planning and implementation of prophylaxis and the maintenance of the production equipment are the key factors for the competitiveness of the industrial enterprises. Proper use of production equipment, as well as the implementation of timely maintenance contribute to the rational use of production resources, reduces the possibility of manufacturing errors (marriage, external remarks, deviations from the required norms and standards in production), shortening the time of production, achieving and maintaining high product quality. (Burns et al., 1991), (Umble et al., 2003), (Olhager, 2013), (Schmitt et al., 1984)

Structure and functions of the management system. The final results of the enterprise depend on clear planning and rational use of production facilities, control over all stages of the production process and the use of management methods and techniques to deal with current problems and their 
consequences. Therefore, the overall management system has a key role in capacity planning and management. (Ahire \& O’Shaughnessy, 1998), (Wasif, 2016)

The degree of information technology and software products utilization in the horizontal and vertical communication in the organization, as well as the strong communication and coordination between the units in the organization are those key factors whose influence proves the need for proper understanding and coordination of the communication between the employees and senior management; essential prerequisites and driving force for achieving full coherence and competitive advantage of production. (Bartels et al., 2010)

Rational use of resources - the influence of this factor is expressed in the development, maintenance and coordination of the production function with other functional units related to the production process in the industrial enterprise. (Swamidass, 2000), (Radojicic et al., 2016)

Management of the labor force qualifications - in order for an industrial enterprise to be competitive in the modern and rapidly changing economic situation, one of the key factors is the qualification of the labor force and its management.

Employee commitment to the goals of the organization consists in building an active relationship between the goals and the vision of senior management for the development and improvement of the industrial enterprise and the goals and motivation of employees. The main driving forces, as well as the commitment of the senior management can again be indicated by the desire, motivation, abilities and principles of employees to achieve coherence and equivalence between organizational goals and requirements of end users. (Schimitzek, 2004)

Organizational culture - building an organizational culture is a key factor influencing the production management and capacity associated with providing and managing the circumstances in the transmission of information and assignment of tasks. (Frost, 1985)

Analysis of the results of management decisions, risks, benefits and feedback is one of the main factors whose influence enables the production company to generate and explore all alternatives in making decisions on the production capacity in order to achieve high efficiency. (Ahire \& O’Shaughnessy, 1998), (Wasif, 2016)

Flexibility and timely response to problems, as well as the use of management methods and techniques to deal with current problems and their consequences - the role of this group of factors is to help the industrial enterprise to respond in a timely manner to the constant changes and challenges of today's business environment in achieving the most effective way to improve product quality and increase production. (Ahire \& O'Shaughnessy, 1998), (Shimizu \& Hitt, 2004), (Wasif, 2016)

To achieve the main goal of the present study, the principles of the methodology for building an effective organizational coordination model in competitive engineering, developed by Panayotova, T. (Panayotova, 2004) have been refined and upgraded through the methodology for interpretive structural modeling (ISM) to help determine the relationship between the identified key factors.

Interpretive Structural Modeling (ISM) is a group technique that can be used to generate multiple hypotheses / solutions to the various challenges posed by the modern and fast-growing business environment.

In ISM, the important elements / factors of a problem or system are identified and listed, using built and analyzed relationships such as dependence, influence and attitude (Frost, 1985).

ISM is a model used to study the factors influencing the effective planning and management of production capacity, which consists of the following main steps: (Ahire \& O'Shaughnessy, 1998)

1. Analysis of the scientific literature to identify key factors relevant to the effective planning and management of the production capacity of the industrial enterprise.

2. Determining the relationship between each of these factors and capacity management.

3. Analysis of the relationships between the studied key factors, using a structural interaction matrix (SSIM)

4. Development of a reachability matrix by SSIM.

5. Based on the relationships given above in the reachability matrix, a diagram of the dependencies of the key factors is constructed.

6. Classification of key factors into 4 main categories: independent, dependent, interdependent, driving 
7. Analysis of the obtained results.

8. Formulation of conclusions.

Based on the determination of the interrelations between the identified key factors influencing the production capacity, a structural matrix of the interaction of the factors (VAXO-matrix) has been developed. Table 2.

Table 2. Structural matrix of the interaction of factors (VAXO-matrix)

\begin{tabular}{|c|c|c|c|c|c|c|c|c|c|c|c|c|c|c|c|c|c|c|}
\hline j/ i-> & F1 & F2 & F3 & F4 & F5 & F6 & F7 & F8 & F9 & F10 & F11 & F12 & F13 & F14 & F15 & F16 & F17 & F18 \\
\hline F1 & & $\mathrm{V}$ & $\mathrm{V}$ & $\mathrm{V}$ & $\mathrm{V}$ & $\mathrm{V}$ & $\mathrm{V}$ & $\mathrm{V}$ & $\mathrm{V}$ & $\mathrm{V}$ & $\mathrm{V}$ & $\mathrm{V}$ & $\mathrm{V}$ & $\mathrm{V}$ & $\mathrm{V}$ & $\mathrm{V}$ & $\mathrm{V}$ & $\mathrm{V}$ \\
\hline $\mathrm{F} 2$ & & & $\mathrm{X}$ & $\mathrm{X}$ & $\mathrm{V}$ & $\mathrm{X}$ & $\mathrm{V}$ & $\mathrm{V}$ & $\mathrm{X}$ & $\mathrm{O}$ & $\mathrm{X}$ & $\mathrm{X}$ & $\mathrm{A}$ & $\mathrm{V}$ & $\mathrm{O}$ & $\mathrm{X}$ & $\mathrm{V}$ & $\mathrm{O}$ \\
\hline $\mathrm{F} 3$ & & & & $\mathrm{X}$ & $\mathrm{V}$ & $\mathrm{X}$ & $\mathrm{V}$ & $\mathrm{V}$ & $\mathrm{A}$ & $\mathrm{A}$ & $\mathrm{V}$ & $\mathrm{O}$ & $\mathrm{V}$ & $\mathrm{A}$ & $\mathrm{X}$ & $\mathrm{V}$ & $\mathrm{V}$ & $\mathrm{V}$ \\
\hline $\mathrm{F} 4$ & & & & & $\mathrm{X}$ & $\mathrm{X}$ & $\mathrm{X}$ & $\mathrm{X}$ & $\mathrm{A}$ & $\mathrm{X}$ & $\mathrm{X}$ & $\mathrm{X}$ & $\mathrm{A}$ & $\mathrm{A}$ & $\mathrm{X}$ & $\mathrm{X}$ & $\mathrm{X}$ & $\mathrm{X}$ \\
\hline F5 & & & & & & $\mathrm{X}$ & $\mathrm{V}$ & $\mathrm{V}$ & $\mathrm{A}$ & $\mathrm{V}$ & $\mathrm{X}$ & $\mathrm{X}$ & $\mathrm{X}$ & $\mathrm{V}$ & $\mathrm{X}$ & $\mathrm{A}$ & $\mathrm{A}$ & $\mathrm{X}$ \\
\hline F6 & & & & & & & $\mathrm{X}$ & $\mathrm{A}$ & $\mathrm{A}$ & $\mathrm{A}$ & $\mathrm{A}$ & $\mathrm{O}$ & $\mathrm{O}$ & $\mathrm{A}$ & $\mathrm{A}$ & $\mathrm{X}$ & $\mathrm{O}$ & $\mathrm{A}$ \\
\hline F7 & & & & & & & & $\mathrm{X}$ & $\mathrm{A}$ & $\mathrm{O}$ & $\mathrm{A}$ & $\mathrm{A}$ & $\mathrm{A}$ & $\mathrm{A}$ & $\mathrm{X}$ & $\mathrm{X}$ & $\mathrm{A}$ & $\mathrm{X}$ \\
\hline F8 & & & & & & & & & $\mathrm{A}$ & $\mathrm{O}$ & $\mathrm{A}$ & $\mathrm{X}$ & $\mathrm{X}$ & $\mathrm{V}$ & $\mathrm{X}$ & $\mathrm{X}$ & $\mathrm{V}$ & $\mathrm{A}$ \\
\hline F9 & & & & & & & & & & $\mathrm{V}$ & $\mathrm{X}$ & $\mathrm{V}$ & $\mathrm{V}$ & $\mathrm{V}$ & $\mathrm{X}$ & $\mathrm{V}$ & $\mathrm{V}$ & $\mathrm{A}$ \\
\hline F10 & & & & & & & & & & & $\mathrm{X}$ & $\mathrm{O}$ & $\mathrm{O}$ & $\mathrm{O}$ & $\mathrm{V}$ & $\mathrm{V}$ & $\mathrm{X}$ & $\mathrm{V}$ \\
\hline F11 & & & & & & & & & & & & $\mathrm{V}$ & $\mathrm{V}$ & $\mathrm{X}$ & $\mathrm{X}$ & $\mathrm{A}$ & $\mathrm{A}$ & $\mathrm{A}$ \\
\hline F12 & & & & & & & & & & & & & $\mathrm{V}$ & $\mathrm{A}$ & $\mathrm{A}$ & $\mathrm{X}$ & $\mathrm{X}$ & $\mathrm{X}$ \\
\hline F13 & & & & & & & & & & & & & & $\mathrm{X}$ & $\mathrm{A}$ & $\mathrm{O}$ & $\mathrm{O}$ & $\mathrm{O}$ \\
\hline F14 & & & & & & & & & & & & & & & $\mathrm{A}$ & $\mathrm{O}$ & $\mathrm{X}$ & $\mathrm{X}$ \\
\hline F15 & & & & & & & & & & & & & & & & $\mathrm{X}$ & $\mathrm{V}$ & $\mathrm{V}$ \\
\hline F16 & & & & & & & & & & & & & & & & & $\mathrm{X}$ & $\mathrm{X}$ \\
\hline F17 & & & & & & & & & & & & & & & & & & $\mathrm{X}$ \\
\hline F18 & & & & & & & & & & & & & & & & & & \\
\hline
\end{tabular}

A contextual relationship "leads to" was used to analyze factors. To develop contextual relationships between variables, a brainstorming technique is considered. VAXO matrix was used to express the relationship between the various factors for effective planning and management of production capacity. Four symbols were used to indicate the direction of the relationship between parameters $i$ and $j$ (here $i$ $<\mathrm{j}$ ), as follows: (Attri et al., 2013), (Nel, 2006)

- V: parameter i will lead to parameter $\mathrm{j}$;

- A: parameter $\mathrm{j}$ will lead to parameter $\mathrm{i}$;

- X: parameters $\mathrm{i}$ and $\mathrm{j}$ will lead to each other;

- O: parameters $i$ and $j$ are not connected.

The resulting SSIM (VAXO-matrix) is converted into a binary matrix, called the initial reach matrix, replacing $\mathrm{V}, \mathrm{A}, \mathrm{X}$ and $\mathrm{O}$ with 1 and 0 as appropriate. The replacement of the characters with 1 and 0 is according to the following rules:

(1) If the entry (i, j) in SSIM is V, the entry (i,j) in the accessibility matrix becomes 1 and the entry (j, i) becomes 0 .

(2) If the record $(i, j)$ in SSIM is A, the record $(i, j)$ in the accessibility matrix becomes 0 and the record $(\mathrm{j}, \mathrm{i})$ becomes 1 .

(3) If the record (i, j) in SSIM is X, the record (i, j) in the accessibility matrix becomes 1 and the record $(\mathrm{j}, \mathrm{i})$ also becomes 1 .

(4) If the entry $(i, j)$ in SSIM is $O$, the entry $(i, j)$ in the accessibility matrix becomes 0 and the entry (j, i) also becomes 0 .

Following the above rules, an initial matrix of reach of the key factors influencing the effective planning and management of the production capacity is constructed (Table 3 ). 
Table 3. Initial reachability matrix

\begin{tabular}{|c|c|c|c|c|c|c|c|c|c|c|c|c|c|c|c|c|c|c|}
\hline j/ i-> & F1 & F2 & F3 & F4 & F5 & F6 & F7 & F8 & F9 & F10 & F11 & F12 & F13 & F14 & F15 & F16 & F17 & F18 \\
\hline F1 & 1 & 1 & 1 & 1 & 1 & 1 & 1 & 1 & 1 & 1 & 1 & 1 & 1 & 1 & 1 & 1 & 1 & 1 \\
\hline F2 & 0 & 0 & 1 & 1 & 1 & 1 & 1 & 1 & 1 & 0 & 1 & 1 & 0 & 1 & 0 & 1 & 1 & 0 \\
\hline F3 & 0 & 1 & 0 & 1 & 1 & 1 & 1 & 1 & 0 & 0 & 1 & 0 & 1 & 0 & 1 & 1 & 1 & 1 \\
\hline F4 & 0 & 1 & 1 & 0 & 1 & 1 & 1 & 1 & 0 & 1 & 1 & 1 & 0 & 0 & 1 & 1 & 1 & 1 \\
\hline F5 & 0 & 0 & 0 & 1 & 0 & 1 & 1 & 1 & 0 & 1 & 1 & 1 & 1 & 1 & 1 & 0 & 1 & 1 \\
\hline F6 & 0 & 1 & 1 & 1 & 1 & 0 & 1 & 0 & 0 & 0 & 0 & 0 & 0 & 0 & 0 & 1 & 0 & 0 \\
\hline F7 & 0 & 0 & 0 & 1 & 0 & 1 & 0 & 1 & 0 & 0 & 0 & 0 & 0 & 0 & 1 & 1 & 0 & 1 \\
\hline F8 & 0 & 0 & 0 & 1 & 0 & 1 & 1 & 0 & 0 & 0 & 0 & 1 & 1 & 1 & 1 & 1 & 0 & 0 \\
\hline F9 & 0 & 1 & 1 & 1 & 1 & 1 & 1 & 1 & 0 & 1 & 1 & 1 & 1 & 1 & 1 & 1 & 1 & 0 \\
\hline F10 & 0 & 0 & 1 & 1 & 0 & 1 & 0 & 0 & 0 & 0 & 1 & 0 & 0 & 0 & 1 & 1 & 1 & 1 \\
\hline F11 & 0 & 1 & 0 & 1 & 1 & 1 & 1 & 1 & 1 & 1 & 0 & 1 & 1 & 1 & 1 & 0 & 1 & 0 \\
\hline F12 & 0 & 1 & 0 & 1 & 1 & 0 & 1 & 1 & 0 & 0 & 0 & 0 & 1 & 0 & 0 & 1 & 0 & 1 \\
\hline F13 & 0 & 1 & 0 & 1 & 1 & 0 & 1 & 1 & 0 & 0 & 0 & 0 & 0 & 1 & 0 & 0 & 1 & 0 \\
\hline F14 & 0 & 0 & 1 & 1 & 0 & 1 & 1 & 0 & 0 & 0 & 1 & 1 & 1 & 0 & 0 & 0 & 0 & 1 \\
\hline F15 & 0 & 0 & 1 & 1 & 1 & 1 & 1 & 1 & 1 & 0 & 1 & 1 & 1 & 1 & 0 & 1 & 1 & 1 \\
\hline F16 & 0 & 1 & 0 & 1 & 1 & 1 & 1 & 1 & 0 & 0 & 1 & 1 & 0 & 0 & 1 & 0 & 1 & 1 \\
\hline F17 & 0 & 0 & 0 & 1 & 1 & 0 & 1 & 0 & 0 & 1 & 1 & 1 & 0 & 1 & 0 & 1 & 0 & 1 \\
\hline F18 & 0 & 0 & 0 & 1 & 1 & 1 & 1 & 1 & 1 & 0 & 1 & 1 & 0 & 1 & 0 & 1 & 1 & 0 \\
\hline
\end{tabular}

Table 4. Final reachability matrix

\begin{tabular}{|c|c|c|c|c|c|c|c|c|c|c|c|c|c|c|c|c|c|c|c|c|}
\hline j/ i- & F1 & F2 & F3 & F4 & F5 & F6 & F7 & F8 & F9 & F10 & F11 & F12 & F13 & F14 & F15 & F16 & F17 & F18 & Drij & Drij\% \\
\hline F1 & 1 & 1 & 1 & 1 & 1 & 1 & 1 & 1 & 1 & 1 & 1 & 1 & 1 & 1 & 1 & 1 & 1 & 1 & 18 & 9,4 \\
\hline F2 & 0 & 0 & 1 & 1 & 1 & 1 & 1 & 1 & 1 & 0 & 1 & 1 & 0 & 1 & 0 & 1 & 1 & 0 & 12 & 6,3 \\
\hline F3 & 0 & 1 & 0 & 1 & 1 & 1 & 1 & 1 & 0 & 0 & 1 & 0 & 1 & 0 & 1 & 1 & 1 & 1 & 12 & 6,3 \\
\hline F4 & 0 & 1 & 1 & 0 & 1 & 1 & 1 & 1 & 0 & 1 & 1 & 1 & 0 & 0 & 1 & 1 & 1 & 1 & 13 & 6,8 \\
\hline F5 & 0 & 0 & 0 & 1 & 0 & 1 & 1 & 1 & 0 & 1 & 1 & 1 & 1 & 1 & 1 & 0 & 1 & 1 & 12 & 6,3 \\
\hline F6 & 0 & 1 & 1 & 1 & 1 & 0 & 1 & 0 & 0 & 0 & 0 & 0 & 0 & 0 & 0 & 1 & 0 & 0 & 6 & 3,1 \\
\hline F7 & 0 & 0 & 0 & 1 & 0 & 1 & 0 & 1 & 0 & 0 & 0 & 0 & 0 & 0 & 1 & 1 & 0 & 1 & 6 & 3,1 \\
\hline F8 & 0 & 0 & 0 & 1 & 0 & 1 & 1 & 0 & 0 & 0 & 0 & 1 & 1 & 1 & 1 & 1 & 0 & 0 & 8 & 4,2 \\
\hline F9 & 0 & 1 & 1 & 1 & 1 & 1 & 1 & 1 & 0 & 1 & 1 & 1 & 1 & 1 & 1 & 1 & 1 & 0 & 15 & 7,9 \\
\hline F10 & 0 & 0 & 1 & 1 & 0 & 1 & 0 & 0 & 0 & 0 & 1 & 0 & 0 & 0 & 1 & 1 & 1 & 1 & 8 & 4,2 \\
\hline F11 & 0 & 1 & 0 & 1 & 1 & 1 & 1 & 1 & 1 & 1 & 0 & 1 & 1 & 1 & 1 & 0 & 1 & 0 & 13 & 6,8 \\
\hline F12 & 0 & 1 & 0 & 1 & 1 & 0 & 1 & 1 & 0 & 0 & 0 & 0 & 1 & 0 & 0 & 1 & 0 & 1 & 8 & 4,2 \\
\hline F13 & 0 & 1 & 0 & 1 & 1 & 0 & 1 & 1 & 0 & 0 & 0 & 0 & 0 & 1 & 0 & 0 & 1 & 0 & 7 & 3,7 \\
\hline F14 & 0 & 0 & 1 & 1 & 0 & 1 & 1 & 0 & 0 & 0 & 1 & 1 & 1 & 0 & 0 & 0 & 0 & 1 & 8 & 4,2 \\
\hline F15 & 0 & 0 & 1 & 1 & 1 & 1 & 1 & 1 & 1 & 0 & 1 & 1 & 1 & 1 & 0 & 1 & 1 & 1 & 14 & 7,3 \\
\hline F16 & 0 & 1 & 0 & 1 & 1 & 1 & 1 & 1 & 0 & 0 & 1 & 1 & 0 & 0 & 1 & 0 & 1 & 1 & 11 & 5,8 \\
\hline F17 & 0 & 0 & 0 & 1 & 1 & 0 & 1 & 0 & 0 & 1 & 1 & 1 & 0 & 1 & 0 & 1 & 0 & 1 & 9 & 4,7 \\
\hline F18 & 0 & 0 & 0 & 1 & 1 & 1 & 1 & 1 & 1 & 0 & 1 & 1 & 0 & 1 & 0 & 1 & 1 & 0 & 11 & 5,8 \\
\hline Depij & 1 & 9 & 8 & 17 & 13 & 14 & 16 & 13 & 5 & 6 & 12 & 12 & 9 & 10 & 10 & 13 & 12 & 11 & 191 & \\
\hline Dep\%ij & 0,5 & 4,7 & 4,2 & 8,9 & 6,8 & 7,3 & 8,4 & 6,8 & 2,6 & 3,1 & 6,3 & 6,3 & 4,7 & 5,2 & 5,2 & 6,8 & 6,3 & 5,8 & & \\
\hline
\end{tabular}

Table 4 presents two main characteristics: driving force (Drij\%) and dependence (Depij\%) of all studied factors influencing the effective planning and management of production capacity in the present study.

The driving force (Drij) for each of the factors is determined according to the dependence (1), and the percentage of the driving forces of the factors is determined by the dependence (2).

$$
\text { Drij }=\sum \mathrm{j} \text { eij }
$$

$$
\left.\operatorname{Dr} \% i j=\left(\sum_{j} e_{i j}\right) * 100\right) /\left(\sum_{j} D_{r i j}\right)
$$


The value of the dependence (Depij) and its percentage are calculated according to the dependences (3) and (4).

$$
\begin{gathered}
\text { Depij }=\sum i \text { eij } \\
\text { Dep } \left.\% i j=\left(\sum_{i} e_{i j}\right) * 100\right) /\left(\sum_{i} D_{e p i j}\right)
\end{gathered}
$$

\section{Classification of key factors influencing the effective planning and management of production capacity}

The values of the driving force and the dependence of each of the considered key factors are studied, and their percentage values are determined. The factors presented above, influencing the production capacity and the calculated values of the driving force and the dependence of each of them, help to classify them into 4 main categories: independent, dependent, interdependent and driving (Fig. 1).

Based on the calculations, a diagram of the dependences of the key factors is presented (Fig. 1).

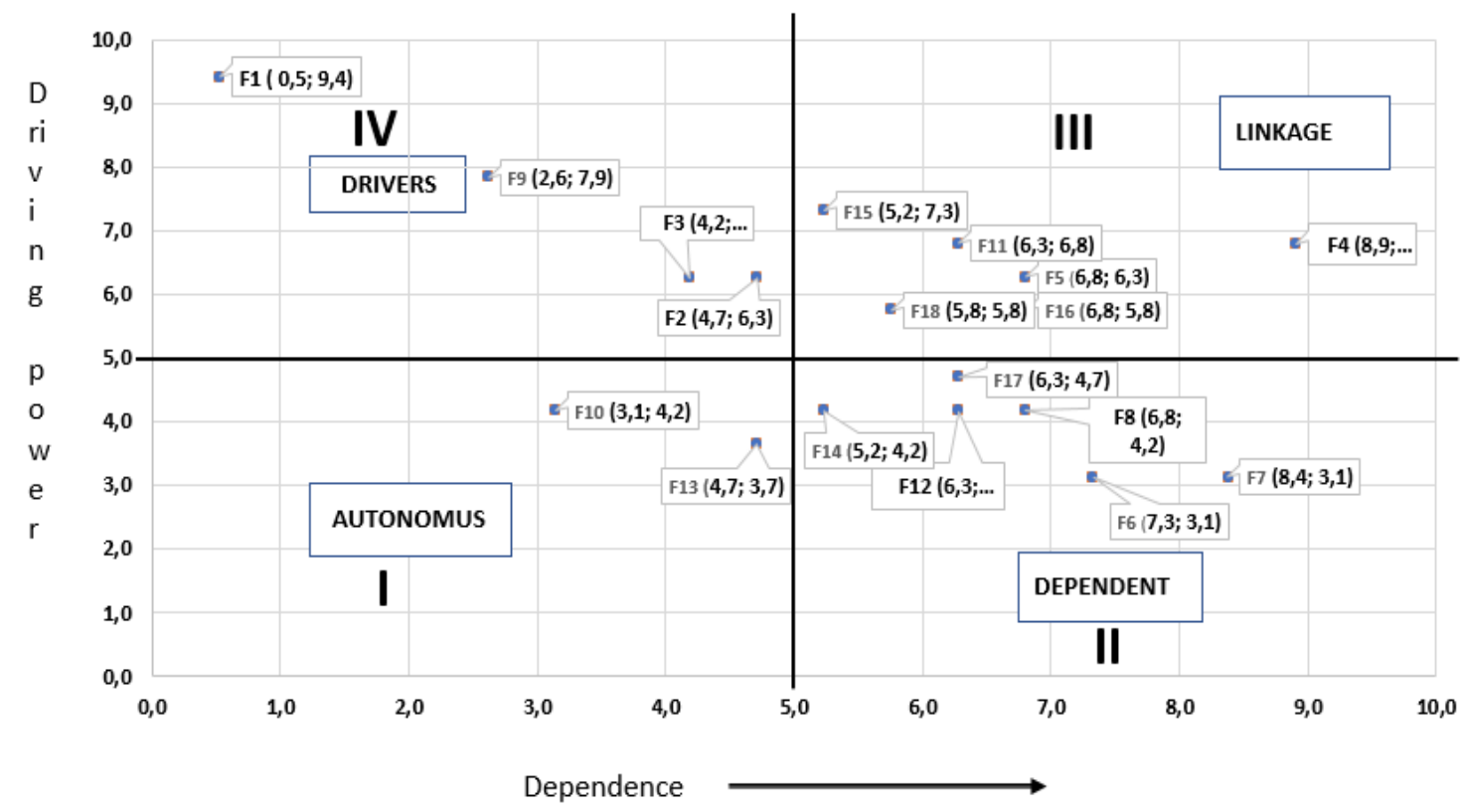

Fig. 1. Diagram of the dependencies of the key factors.

The independent (autonomous) factors are characterized by weak driving force and low dependence. These factors are characterized by their autonomy - they are not directly influenced by other factors. The group of independent factors (Fig. 1) includes a total of 2 of 18 factors, namely: Degree of information technology and software products utilization in the horizontal and vertical communication in the organization (F10) and Management of workforce qualification (F13). Independent factors play a key role in the implementation of effective planning and management of the production capacity of the industrial enterprise.

The dependent factors are determined by weak driving force but strong dependence. Their change does not directly affect the others, but they are highly dependent on the change of the other key factors. This group includes a total of 6 of 18 factors: Mechanization and automation of production (F6), Degree of efficiency and use of production equipment (F7), Planning and implementation of prevention and maintenance of production equipment (F8), Rational use of resources (F12), Employee engagement with the organization's goals (F14) and Flexibility and timely response to a problem (F17). 
The next group of factors is characterized by a_strong driving force and strong dependence, namely - the interdependent ones. Of the studied factors in this classification fall a total of 6 out of 18. They are: Planning and effective management of production capacity (F4), Level of organization of production (F5), Effective communication and coordination between units in the organization (F11), Organizational culture F15), Analysis of the results of management decisions, risks, benefits and feedback (F16) and the proper Usage of management methods and techniques in dealing with the current problems and their consequences (F18)).

Drivers. The factors included in this part of the diagram have a strong driving force, but a weak dependence. This part of the chart includes the other 4 factors - Senior Management Commitment (F1), Corporate and Production Strategy (F2), Resource Planning (F3) and Management System Structure and Functions (F9) .

\section{Conclusions}

The proposed methodology for studying the key factors that have a profound unfluence on the effective planning and management of production capacity shows the relationship between different factors and their classification into 4 main groups. The diagram of the dependences of the key factors divides the factors into four categories such as: independent, dependent, interdependent and driving, due to which the analysis of the factors becomes easier..

- The independent factors do not influence the other studied factors.

- There is no single factor that has a strong driving force as well as a strong dependence. Thus, it can be concluded that among all the 18 factors selected in this study, none is unstable.

- There is not a single factor that stands out with both a weak driving force and low dependence. This proves that the surveyed factors play a crucial role in the effective management and planning of production capacity and justifies the need to examine the relationships between the factors that have been previously identified .

- The dependency chart presents key factors such as senior management engagement, corporate and production strategy, resource planning and the structure and functions of the management system at the top left of the model, characterized by a strong driving force. It is on these driving factors that production managers need to pay special attention, because they are the main drivers for achieving effective planning and management of the production capacity of the industrial enterprise.

- Factors such as: mechanization and automation of production, degree of efficiency and use of production equipment, planning and implementation of prevention and maintenance of production equipment, rational use of resources, employee commitment to the goals of the organization and flexibility and timely response. These are the dependent factors that production managers need to pay close attention to. These factors are complex, and this necessitates a more careful analysis to determine and manage their significance for the manufacturing plant.

- Defined as interdependent factors: planning and effective management of production capacity, level of production organization, effective communication and coordination between units in the organization, organizational culture, analysis of the results of management decisions, risks, benefits and feedback, and use of management methods and techniques for dealing with current problems and their consequences are unstable due to the fact that any change that has occurred in them will have an effect on others, as well as feedback for themselves. These factors are complex, which makes it necessary for the production managers to analyze and apply them more carefully and thoroughly.

- The driving factors with a strong driving force, but weak dependence are those that have a strategic role in the organization, development and improvement of production management of the industrial enterprise.

Developed in the present paper, through the use of ISM, is a model of the relationships and interrelationships between different key factors. The modeling of the structural equation, also known as the linear approach to structural connection, can be applied to test the validity of such a hypothetical model and is the subject of future research. Practical testing of the proposed model in various enterprises operating in the field of mechanical engineering in Bulgaria is forthcoming. Of particular interest to the 
research team are machine-building enterprises operating on a projects principle. Depending on the results, the team will proceed with its work on the model optimization and integration of some of the proposed key factors in order to reduce their number.

\section{Acknowledgements}

This study was implemented as part of a project for doctoral students support PD4/2020 within the Department of Industrial Management at the Technical University of Varna and the research work on this topic will continue after its completion.

\section{References}

Ahire, L.S., \& O'Shaughnessy, K. (1998). The role of top management commitment in quality management: an empirical analysis of the auto parts industry. International Journal of Quality Science, 3(1), 5-37. https://doi.org/10.1108/13598539810196868

Attri, R., Dev, N., Sharma, V. (2013). Interpretative Structural Modelling (ISM) approach: An Overview, Res. J. Management Sci., 2319(2), 1171.

Chase, R.B. \& Zhang, A. (1998), "Operations management: internationalization and interdisciplinary integration", International Journal of Operations \& Production Management, 18(7), 663667. https://doi.org/10.1108/01443579810217648

Dima, I. C. (Ed.). (2013). Industrial production management in flexible manufacturing systems. IGI Global. (pp 41-45). https://doi.org/10.4018/978-1-4666-2818-2

Frost, P. J., Moore, L. F., Louis, M. R. E., Lundberg, C. C., \& Martin, J. E. (1985). Organizational culture. Sage Publications, Inc.

Gupta, S., \& Starr, M. K. (2014). Production and operations management systems. Boca Raton, FL: CRC Press. (pp 134-136). https://doi.org/10.1201/b16470

Krishnaswamy, K. N., Sivakumar, A. I., \& Mathirajan, M. (2006). Management research methodology: Integration of principles, methods and techniques. Pearson Education India. (pp 91-92).

Makedonska, D., Dimitrov, Iv. (1997). Production Management. Varna. (pp 75- 78).

Nel, W. (2 $2^{\text {nd }}$ ed., 2006). Management for engineers, technologists and scientists. Juta and Company Ltd.

Panayotova, T. (2004). Modeling of organizational relations in the development of complex project tasks in the conditions of Competitive Engineering . Abstract of a $\mathrm{PhD}$ dissertation

Sage, A. (1977). Interpretive Structural Modelling: Methodology for Large-scale Systems. New York, NY: Mc Graw-Hill, pp 91-164.

Schimitzek, P. (2004). The Efficient Enterprise: Increased Corporate Success with Industry-Specific Information Technology and Knowledge Management. CRC Press.

Sharpe, M.E. (1979). Problems of Economics. (pp 4-5).

Swamidass, P. M. (Ed.). (2000). Encyclopedia of production and manufacturing management. Springer Science \& Business Media. https://doi.org/10.1007/1-4020-0612-8 
Bartels, J., Peters, O., de Jong, M., Pruyn, A., \& van der Molen, M. (2010). Horizontal and vertical communication as determinants of professional and organisational identification. Personnel Review. https://doi.org/10.1108/00483481011017426

Behl, A., \& Pal, A. (2020). Interpretive Structural Modeling: Background, Concepts, and Application. In Multi-Criteria Decision Analysis in Management (pp. 1-27). IGI Global. https://doi.org/10.4018/978-1-7998-2216-5.ch001

Brönner, M., Wolff, S., Jovanovic, J., Keuthen, K., \& Lienkamp, M. (2020). Production Strategy Development: Simulation of Dependencies Using Recurrent Fuzzy Systems. Systems, 8(1), 1. https://doi.org/10.3390/systems8010001

Burns, O. M., Turnipseed, D., \& Riggs, W. E. (1991). Critical success factors in manufacturing resource planning implementation. International Journal of Operations \& Production Management.

DuBrin, A. J. ( $8^{\text {th }}$ ed. 2008). Essentials Of Management. Cengage Learning, USA

Olhager, J. (2013). Evolution of operations planning and control: from production to supply chains. International journal of production research,51(23-24), 6836-6843. https://doi.org/10.1080/00207543.2012.761363

Radojičić, M., Vasović, J. , Paunović, Vl., \& Nesic, Z. (2016). An analysis of capacity utilization in industrial production in function of rational resource use. https://doi.org/10.5937/IMK1603091R

Shimizu, K., \& Hitt, M. A. (2004). Strategic flexibility: Organizational preparedness to reverse ineffective strategic decisions. Academy of Management Perspectives, 18(4), 44-59. https://doi.org/10.5465/ame.2004.15268683

Umble, E. J., Haft, R. R., \& Umble, M. M. (2003). Enterprise resource planning: Implementation procedures and critical success factors. European journal of operational research, 146(2), 241257. https://doi.org/10.1016/S0377-2217(02)00547-7

Wasif, S. M. (June 11, 2016). Standards Of Top Management Commitment. eLearning Industry. Retrieved May 21, 2016 from https://elearningindustry.com/standards-top-managementcommitment.

Winroth, M., Säfsten, K., Lindström, V., Frohm, J., \& Stahre, J. (2006). Automation strategiesrefinement of manufacturing strategy content. In Proceeding of 17th Annual Conference of POMS: The new world uncertainties, Boston, MA, April.

Schmitt, T. G., Berry, W. L., \& Vollmann, T. E. (1984). An analysis of capacity planning procedures for a material requirements planning system. Decision Sciences, 15(4), 522-541. https://doi.org/10.1111/j.1540-5915.1984.tb01240.x 